\title{
The savant syndrome
}

\author{
Genius and mental handicap combined
}

\section{J. A. M. SCHIPPERHeIn, Locum Senior Registrar in Psychiatry, Napsbury Hospital, Herts; and F. J. DunNe, Consultant Psychiatrist, Warley Hospital, Brentwood, Essex CM14 5HQ}

Idiot-savants are people of low intelligence who have one or two outstanding talents such as calendar calculation, drawing, or musical performance. The syndrome occurs with high frequency among autistic children (autism is about four times commoner in boys), and the male to female ratio is about $6: 1$ suggesting a sex linked disorder (Hill, 1977). It is estimated to occur in $0.06 \%$ of the mentally handicapped population or about 1 in 2,000 of those living in institutions (Treffert, 1988). The gift starts apparently spontaneously between age 5 and 8 years. Frequently the parents claim that they themselves do not have the talent and know of no one in the family who has, but there is a tendency for savant skills to run in families, suggesting that genetic factors play a role.

The syndrome was first described by Langdon Down in 1887 but Tredgold (1914) wrote the first definitive account of the condition. Several types are found: calendar calculators, artists, musicians and mnemonists. The condition can be congenital, or acquired in an otherwise normal individual following injury to or disease of the central nervous system.

The skills can appear suddenly and likewise disappear without explanation. Regardless of their particular ability, savants all have in common a phenomenal memory. The term itself is a misnomer being derived from the obsolete definition 'idiot' denoting an individual with an IQ of 25 or below, and the word 'savant' or knowledgeable person from the French 'savoir' meaning, 'to know'. Most savants have a very low IQ, otherwise they would not be classified as such. Communication problems are common and include low-level grammatical grasp, slowness, mutism, complete absence of speech, hesitant speech, withdrawal and autism (O'Connor, 1989).

Calendar calculators and savants with mathematical ability and exceptional mnemonic skills are the most frequent; musicians are rare. In some individuals, skills are remarkable because of the associated mental handicap (talented savants); in others (prodigious savants) the abilities would be considered spectacular even if they occurred in normal people. Skills can also occur in combination, for instance, music and memory. Calculators are capable of remarkable feats of mental arithmetic, including the multiplication of three-figure numbers in a few seconds, the rapid calculation of square roots, and the description of a geometric series to 64 places (Hermelin \& O'Connor, 1983). They follow simple rules which are used as an aid to recalling dates and sequences in classical music; the skills though impressive may be confined to tonal music. Rule-based strategies are used by all savants and seem to be IQ independent.

The phenomenal ability of identical, mentally handicapped twins to name the day of the week for a given date in any year has been explained by the capacity to subtract multiples of a 400-year calendar cycle from any given year (Horwitz et al, 1969). Both twins had a very low level of concentration except for questions concerning the calendar. The twins began by memorising a conventional calendar, then noted that one month began where the last left off, and subsequently tacked months together, then years, and so forth. As the 400-year cycle is constant, they could connect any day and date by subtracting multiples of 400 , and were aware of the sub-patterns within the cycle. These feats of memory may not be so astonishing given that the twins devoted their time to practically nothing else from the age of nine onwards; thus, rote memory may be involved. The savant's skill may represent a failure to forget rather than an enhanced ability to store memories; what stands out is the capacity for long-term memory.

Intense practice and appropriate reinforcement have been suggested as alternatives to rote memory. However, it is unlikely that practice alone can account for the capacity of idiots-savants to comprehend the complexities of music, art or mathematics. Sensory deprivation and social isolation may also be involved: both lead to boredom and to the development of bizarre or trivial preoccupations and rituals such as memorising obscure facts and calendar calculating, in a desperate search for stimulation. Some normal individuals in extreme isolation develop feats of mental calculation or rote memory as a way of adapting; the savant may do the same, but most 
people with sensory impairment such as the blind and the deaf do not develop savant skills. Eidetic imagery, an intense coloured visual image which is aroused and maintained by scanning an object and persists for at least $\mathbf{4 0}$ seconds, may be found in the savant calculator but it cannot account for cases in which calculations extend into the future, for which no calendars are available (Giray \& Barclay, 1977).

The left cerebral hemisphere normally develops later than the right and is subject to prenatal influences for a longer period of time. A male factor, perhaps testosterone, might slow growth and impair neuronal migration in the left brain, with subsequent enlargement and shift of dominance to the right brain, thus favouring talents associated with right brain functions (Brink, 1980). Damage to the left hippocampus and amygdala might also be important since both are involved in the regulation of memory functions: the hippocampus is responsible for simple recall and the amygdala for cataloguing and providing emotional tone to memory. Overcompensation by the right hippocampus, for example, could account for the phenomenal memory displayed by savants (Treffert, 1988). Ischaemic or hypoxic injury to the brain either during pregnancy or at birth have also been proposed as causes of the syndrome. Of particular interest is the triad of blindness, musical genius and retardation associated with retrolental fibroplasia, suggesting that high oxygen concentrations might be responsible.
To date, no single theory can explain the savant syndrome but future research using positron emission tomography (PET) scans, nuclear magnetic resonance, cerebral blood flow studies and other brain mapping techniques may help to provide an anatomical explanation for this extraordinary condition.

\section{References}

BrinK, T. L. (1980) Idiot savant with unusual mechanical ability: an organic explanation. American Journal of Psychiatry, 137, 250-251.

GiRAY, E. F. \& BarClay, A. G. (1977) Eidetic imagery: longitudinal results in brain-damaged children. American Journal of Mental Deficiency, 82, 311-314.

HeRmelin, B. \& O'ConNOR, N. (1983) The idiot savant: flawed genius or clever Hans? Psychological Medicine, 13, 479-481.

HiLl, A. L. (1977) Idiots-savants: rate of incidence. Perceptual Motor Skills, 44, 161-162.

HoRWITZ, W. A., DEMING, W. E. \& WiNTER, R. F. (1969) A further account of the idiots savants, experts with the calendar. American Journal of Psychiatry, 126, 412-415.

O'CONNOR, N. (1989) The performance of the 'idiot savant': implicit and explicit. British Journal of Disorders of Communication, 24, 1-20.

Tredgold, A. F. (1914) Mental Deficiency. New York: Wood.

TREFFERT, D. A. (1988) The idiot savant: a review of the syndrome. American Journal of Psychiatry, 145, 563-572.

A full list of references is available on request from the authors. 